\title{
Editorial \\ La responsabilidad de la educación en la formación del gastrónomo colombiano
}

Enseñar no es transferir conocimiento, sino crear las posibilidades para su producción o su construcción. Quien enseña aprende al enseñar y quien enseña aprende a aprender

PAULO FRIERE, Pedagogía del oprimido

Uno de los grandes temas dentro de la Instituciones de Educación Superior enfocadas al desarrollo de carreras en gastronomía, es poder establecer herramientas y modelos que ayuden dentro de la formación de los profesionales; algunos se enfocan en enseñar las técnicas de elaboración de productos, otros en generar la responsabilidad de reconocer una identidad nacional a nivel de las recetas autóctonas de los territorios del país y varios en poder asociar la educación a elementos prácticos que ayuden a identificar la labor organizacional y administrativa que tiene su rol dentro de una empresa en el sector de alimentos.

El programa de Gastronomía de la Fundación Universitaria San Mateo en el proceso de establecer una formación integral a sus estudiantes con la orientación de sus docentes, articula su grupo de investigación "Patrimonio Cultural Gastronómico de Colombia" como plataforma de práctica de los conocimientos desarrollados en el aula de clase, con los elementos culturales, sociales y económicos del territorio del país, permitiendo compartir las experiencias de diversas poblaciones en la conservación de su acervo ancestral que son identificadas dentro de la elaboración de productos culinarios; los cuales fomentan la indagación, el contraste y el desarrollo de habilidades que debe tener el gastrónomo profesional colombiano en el diseño propuestas gastronómicas.

Tomando como eje la pedagogía crítica como lo expone Freire (1985) en su obra La pedagogía del oprimido, la cual está orientada "(...) a contribuir a la concientización de los sujetos, entendida esta como el reconocimiento del mundo, no como un mundo dado, sino como un mundo en construcción" (p. 106) en el cual los estudiantes son los encargados de analizar y deducir las estrategias para la difusión del arraigo de la cocina nacional; como se evidencia en el siguiente número de Sosquua. Revista Especializada en Gastronomía, donde se encontrarán indagaciones realizadas por docentes y jóvenes investigadores (estudiantes) analizando aspectos tales como la reconstrucción de preparaciones autóctonas del Llano, bebidas ancestrales del Caribe y del Pacífico, además de un estudio documental de la historia de los principales eventos gastronómicos que se desarrollan en el 
país. Elementos que conforman la construcción del saber del gastrónomo de la Fundación Universitaria San Mateo, que con la colaboración nacional e internacional sigue en la búsqueda de generar espacios de debate en pro de una identidad gastronómica nacional.

Los invitamos a que nos acompañen con esta nueva experiencia del saber, donde las reflexiones expuestas en este espacio generen canales de formación de la carrera de Gastronomía.

\section{Referencias}

Freire, P. (1985). Pedagogía del oprimido. Nueva York: Herder \& Herder.

ROYER YESID GUTIÉRREZ QUECANO

Grupo de investigación Patrimonio Cultural Gastronómico de Colombia

Fundación Universitaria San Mateo

Editor 